HorTSCIENCE 25(3):294-296. 1990.

\title{
Floral Initiation and Development in Aquilegia
}

\author{
J.W. White ${ }^{1}$, H. Chen ${ }^{2}$, X. Zhang ${ }^{2}$, D.J. Beattie ${ }^{3}$, and H. Grossman ${ }^{4}$ \\ Department of Horticulture, Pennsylvania State University, University \\ Park, PA 16802
}

Additional index words. columbine, scanning electron microscopy

\begin{abstract}
Floral initiation and development of greenhouse and growth room-grown Aquilegia $\times$ hybrida Sims cultivars were studied using a scanning electron microscope. All greenhouse-grown cultivars initiated floral buds before cold treatment, $\approx 5$ months after sowing. Floral initiation occurred at the apical meristem and proceeded acropetally on an elongated conical axis in the sequence: sepals, petals, stamens, stamenodia, and carpels. In a second experiment, 13 Aquilegia cultivars, three of which had been used in the first experiment, were grown as seedlings in a growth room at $20 \mathrm{C}$ under an 8-, 12-, 16-, or $20-\mathrm{hr}$ photoperiod, each totaling $10.2 \mathrm{~mol}^{\circ} \mathrm{day}^{-1} \cdot \mathrm{m}^{-2}$ irradiance from cool-white fluorescent lamps. Here, floral initiation was absent even after 7 months from sowing, presumably because there was no diurnal variation in irradiance or temperature.
\end{abstract}

The shoot apex is the perception site of vernalization (Bernier et al., 1981; Chouard, 1960). In some herbaceous perennials, where flowering is usually preceded each year by vegetative growth, many must reach a critical number of nodes before cold stimulus can be perceived (Chouard, 1960). There is limited information on phase changes in herbaceous perennials. Researchers have used leaf number or crown fresh weight to describe when the transition from juvenile to adult occurs (Bernier et al., 1981), but have not accurately correlated these measurements with changes in meristem anatomy related to floral initiation. If weight or leaf number could be better correlated to when floral initiation occurs, environmental conditions controlling the rate of floral development could be regulated and reliable production schedules developed. The objective of this study was to identify, with a scanning electron microscope (SEM), the morphological stages of floral initiation and development for Aquilegia cultivars grown under various environmental conditions.

Greenhouse. Seeds of the Weddle Song-

Received for publication 24 Oct. 1988. Contribution no. 131, Dept. of Horticulture. Authorized for publication as Paper no. 7997 in the Journal Series of the Pennsylvania Agricultural Experiment Station. The cost of publishing this paper was defrayed in part by the payment of page charges. Under postal regulations, this paper therefore must be hereby marked advertisement solely to indicate this fact.

'Professor.

'Graduate Assistant.

${ }^{3}$ Assistant Professor.

${ }^{4}$ Associate Professor. bird series 'Bluebird', 'Dove', 'Purple', and 'Robin' (Weddle Seed, Palisade, Colo.) were sown in Colorado in late July 1986. When they had four to five leaves in early October, they were shipped to us and transplanted on 14 Oct. They were grown in greenhouses equipped with high-pressure sodium lamps that provided supplemental irradiation of 200 $\mu \mathrm{mol} \cdot \mathrm{s}^{-1} \cdot \mathrm{m}^{-2}$ from 1700 to $0700 \mathrm{HR}$. Thermostats were set at $21 / 15.5 \mathrm{C}$ (day/night), but daytime temperatures occasionally reached 30C. Plants had 12 to 14 leaves when they were exposed to $0,2,4$, or 8 weeks of cold at $4.5 \pm 0.5 \mathrm{C}$ beginning 28 Jan. 1987. Three randomly selected plants of each cultivar were sampled for SEM studies weekly for 6 weeks starting on 10 Dec. 1986 at about the 12- to 14-leaf stage. Morphological changes in the apical meristems were studied with dissecting and scanning-electron microscopes.

Growth room. Seeds of the Benary Music series 'Blue/White', 'Red/White', 'White', and 'Yellow' (Ernst Benary, Hanover, F.R.G.) were sown 1 Mar. 1987. In addition, seeds of the Weddle Songbird series 'Bluebird', 'Bunting', 'Cardinal', 'Chickadee', 'Dove', 'Goldfinch', 'Mockingbird', 'Robin', and 'Tanager' were sown on 26 Mar. 1987. All cultivars were transplanted into cellpacks 1 month after sowing. When the plants had grown to the four- to five-leaf size, they were moved into a growth room held at 20 $\pm 2 \mathrm{C}$ with photoperiods of $8,12,16$, or 20 $\mathrm{hr}$, each totaling $10.2 \mathrm{~mol} \cdot \mathrm{day}^{-1} \cdot \mathrm{m}^{-2}$ irradiance $\left(354,236,177\right.$, or $142 \mu \mathrm{mol} \cdot \mathrm{s}^{-1} \cdot \mathrm{m}^{-2}$ for 8-, 12-, 16-, or 20-hr photoperiods, respectively) provided by $215-\mathrm{W}$ cool-white fluorescent (CWF) lamps by adjusting the distance between plants and lamps. Meristem sampling for SEM studies began when 


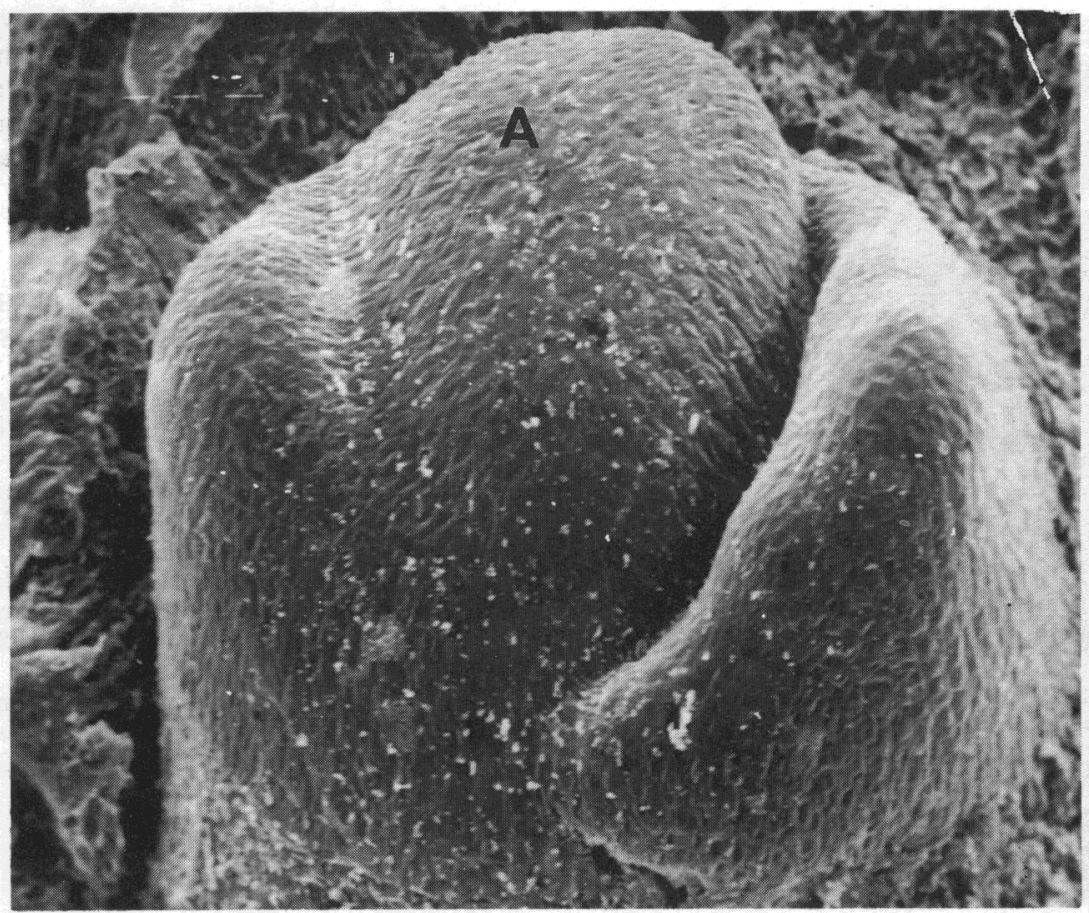

Fig. 1. Apex (A) of vegetative meristem with leaf primordia adjacent to it. (Photographed with SEM at $\times 360)$. Scale line $=10 \mu \mathrm{m}$.

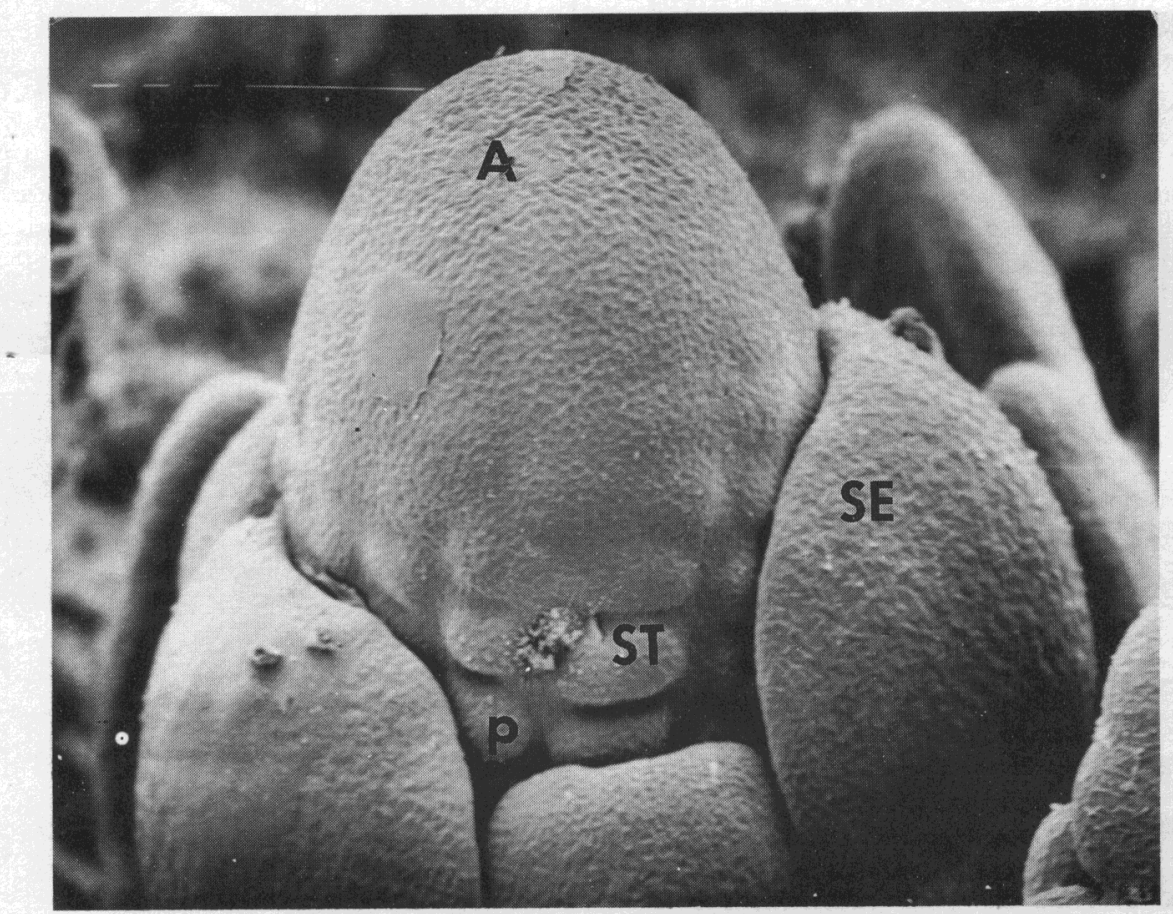

Fig. 2. Early stage of floral initiation showing the apex (A), sepals (SE), petals (P), and stamens (ST). (Photographed with SEM at $\times 180$.) Scale line $=100 \mu \mathrm{m}$.

plants developed seven to eight leaves and continued weekly for 7 months after sowing.

Preparation of plant materials for SEM studies. Three plants were randomly chosen at each sampling time. The apical region was excised and the largest leaves were removed by hand. The crown was cut to leave the apex and a small block of tissue just below the apex. The tissue section was placed in a
Critical Point Dryer (Watford, England). Dried specimens were coated with gold in an ISI-PS-2 sputter-coater and observed in an ISI-60 SEM at magnifications up to $\times 360$.

Greenhouse. Floral initiation occurred without vernalization in 'Bluebird', 'Dove', 'Purple', and 'Robin' by the end of Dec. 1986,5 months after sowing. In the greenhouse, the first visible bud $(\approx 0.4 \mathrm{~cm}$ in diameter) was observed on 23 Jan. 1987 in 'Bluebird' and 'Dove' and on 15 Feb. 1987 in 'Robin' and 'Purple'. We do not know why floral initiation occurred in 'Bluebird', 'Dove', 'Purple', and 'Robin' without vernalization.

Four initiation stages were observed. Vegetative meristems produced leaf primordia in a whorled sequence (Fig. 1). The indication of forthcoming flowering was shown by the development of a terminal bud, often referred to as the crown flower, differentiating acropetally on an elongated conical axis. Despite earlier claims by Gregoire (1938) that the floral apex of aquilegias arose laterally on the vegetative apex, Tepfer (1953) also has shown that the vegetative apex is transformed to a reproductive axis.

The terminal inflorescence developed into a three-parted compound cyme, with additional three-flowered cymes produced several times in numerous lateral inflorescences, each terminating in a crown flower. Young plants with a minimum of 12 to 14 leaves usually produced only one inflorescence, whereas older plants with 18 to 20 leaves produced many inflorescences from a larger basal crown or from multiple crowns. Sepal, petal, then stamen primordia were formed (in that order) during the early stages of initiation (Fig. 2); later, staminode and then carpel primordia were initiated at the apex on an elongated conical axis (Figs. 3 and 4).

Growth room. Further SEM analysis conducted with the 13 Aquilegia cultivars, three of which had been used in the greenhouse, showed no sign of floral initiation up to 7 months after sowing, the termination of the experiment.

The ability to prevent initiation over 7 months of vegetative growth, using controlled environments with no diurnal variation in total irradiance or temperature, would allow growers to produce larger crowns in the first year. These likely would have greater carbohydrate reserves and likely would produce more inflorescences and more florets per inflorescence.

Shedron and Weiler (1982) were not able to distinguish among aguilegia plants that had initiated buds but that had not elongated to a visible bud stage, those with buds that had aborted before becoming visible, and those that did not initiate buds at all. Therefore, the need for cold for initiation was not firmly established in their research, rather only the effect of cold and GA, on bud development to the visible stage. In our growth room experiment, diurnal temperature variation was not used but may be necessary for flower initiation. Also, initiation could be related to a R:FR energy balance not available from CWF lamps only. Further studies are nec- 


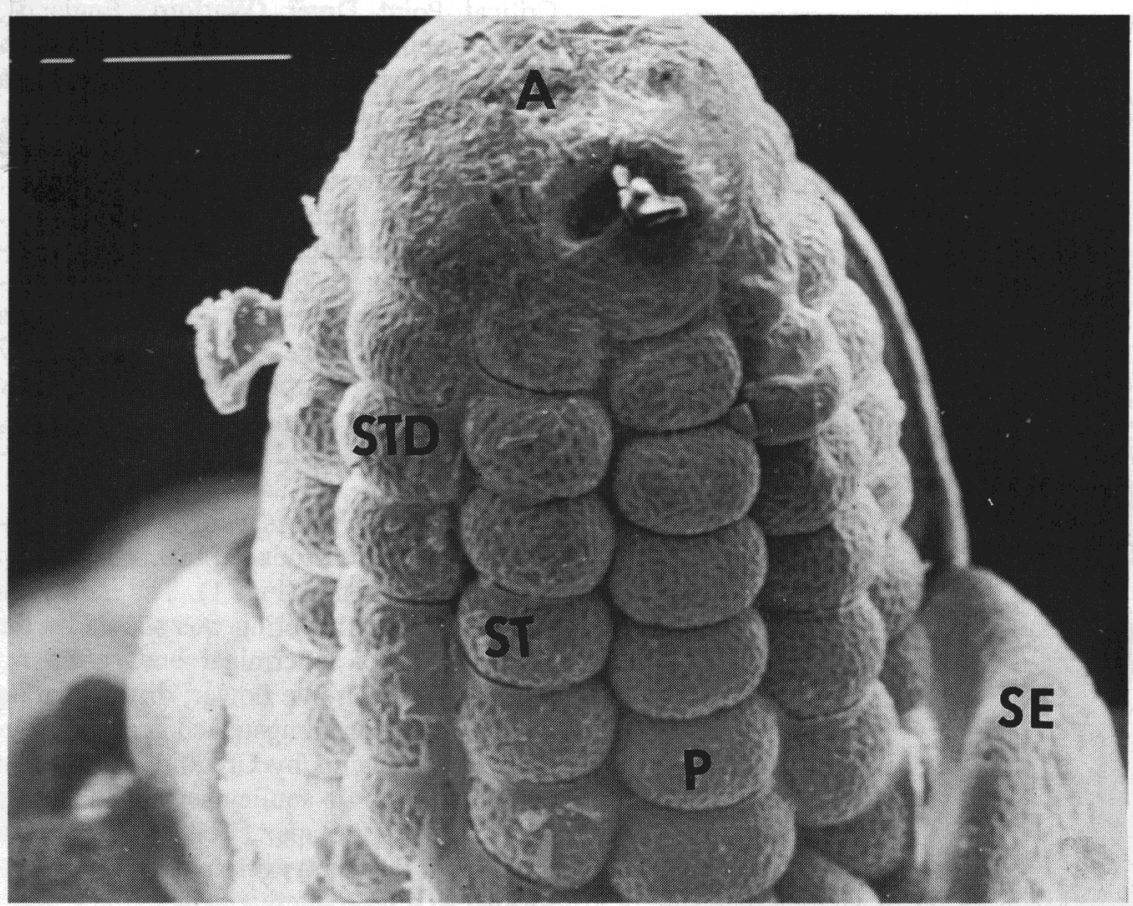

Fig. 3. Later stage of floral organ initiation showing apex (A), sepals (SE), petals (P), stamens (ST), and stamenodia (STD). (Photographed with SEM at $\times 150$.) Scale line $=100 \mu \mathrm{m}$.

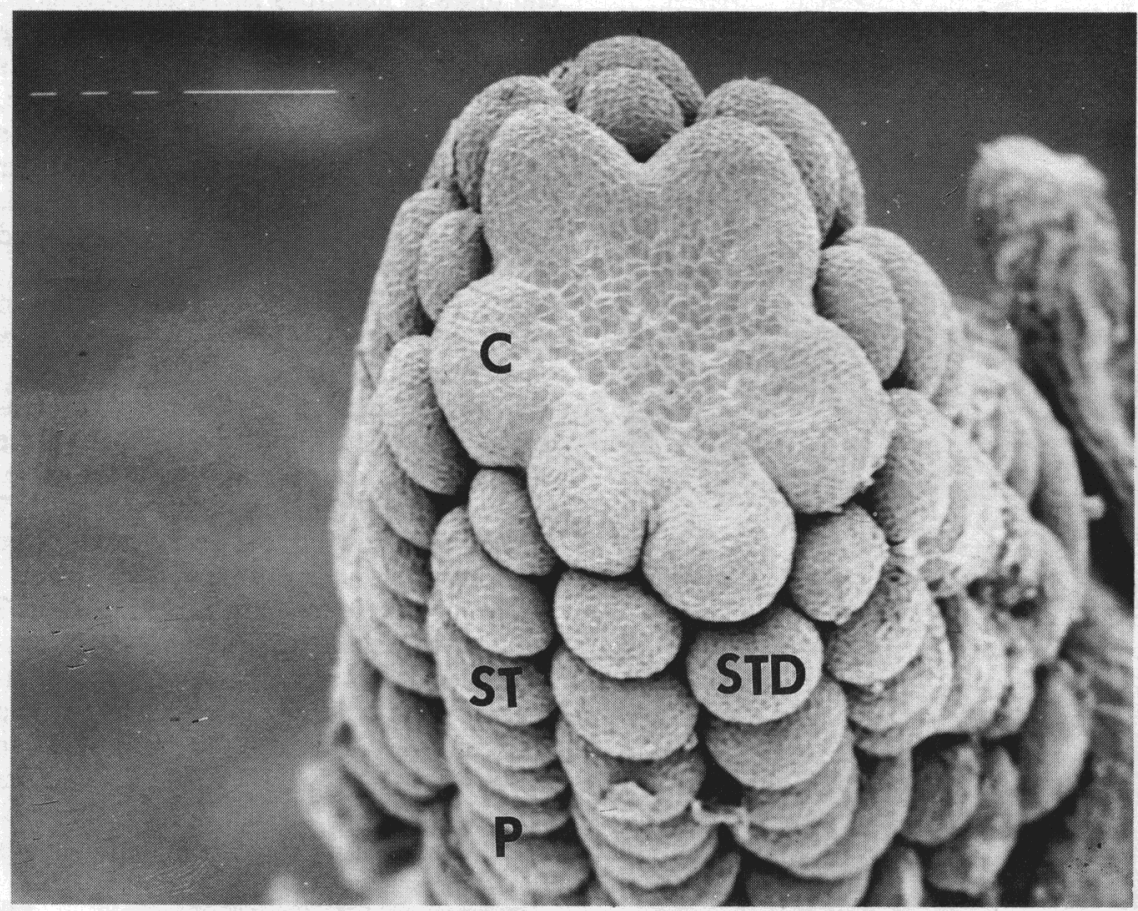

Fig. 4. Final stage of floral initiation showing petals (P), stamens (ST), stamenodia (STD), and carpel (C). (Sepals were removed.) (Photographed with SEM at $\times 180$.) Scale line $=100 \mu \mathrm{m}$. essary for a critical understanding of environmental and chemical effects on the transition time from the vegetative to the reproductive state and for a method or a tool to distinguish among genotypes that have different initiation requirements.

\section{Literature Cited}

Bernier, G., J.-M. Kinet, and R.M. Sachs. 1981. The physiology of flowering. vol. I. CRC Press, Boca Raton, Fla.

Chouard, P. 1960. Vernalization and its relations to dormancy. Annu. Rev. Plant Physiol. 11:191237.

Gregoire, V. 1938. LaMorphogenese et l'autonomie morphologique de l'appareil floral. I. Le carpelle. La Cellule 47:287-452.

Shedron, K.G. and T.C. Weiler. 1982. Regulation of growth and flowering in Aquilegia $\times$ hybrida Sims. J. Amer. Soc. Hort. Sci. 107:878882.

Tepfer, S.S. 1953. Floral anatomy and ontogeny in Aquilegia formosa var. truncata and Ranunculus repens. Univ. of Calif. Bot. 25:513648. 